\title{
Reflexões sobre o Método do Ensino Juridico.
}

\author{
Fábio Konder Comparato
}

Professor Titular de Direito Comercial da Faculdade de Direito da Universidade de São Paulo.

O sentido primigênio de método radica-se em hodos, isto é, a via ou o caminho, com o prefixo meta indicando ligação ou sequiência. $\mathrm{O}$ método é, pois, antes de mais nada, o caminho a ser percorrido; na acepção figurada, a direção correta para se chegar a um resultado. No campo intelectual, a ordenação do pensamento, a investigação racional, a pesquisa. Em acepções secundárias ou complementares, já na filosofia grega, método passou a indicar um trabalho ou obra científica (como em ARIstóteles, Política, 4, 2, 4), uma doutrina (Platão, Teeteta, 183, "c") ou a própria ciência, enquanto oposta à arte (ARISTóTELES, Etica a Nicômaco, I, 1).

Essa sucessão semântica parece bem significativa para a época contemporânea, que não somente tem aprofundado a análise epistemológica, enquanto pressuposto de toda investigação científica, como tende, de certa forma, a reduzir a ciência ao seu próprio método. Assim, quando Lord KEYNES procura caracterizar as ciências sociais, mais como um método do que como uma doutrina (it is a method rather than a doctrine, an apparatus of the mind, a technique of thinking, which helps its possessor to draw correct conclusions), ele indica, na verdade, a linha direcional de todo saber científico, na época contemporânea.

NOTA: Convidado a comparecer, em exíguo prazo, à homenagem que tão justamente se presta a GoFFredo Telles JÚNIOR, por ocasião do seu jubileu na cátedra, vasculhei em meus escritos para encontrar algo que pudesse traduzir, ainda que palidamente, a admiração constante que o discípulo vota ao mestre. Só encontrei estas reflexōes, por mim apresentadas à Comissão de Ensino da Faculdade. Ainda que toscas, elas têm o único mérito de tratar de tema no qual o nosso querido homenageado viu consagrada uma de suas melhores qualidades: a arte de ensinar, por ele transformada naquela espécie de paixäo estética, que 6 esplendor do verdadeiro, como queria Platão. 
As razões dessa tendência parecem assentar na extraordinária aceleração da descoberta científica e da acumulação de fatos históricos, levando o cientista e o pensador a criticar, sistematicamente, o próprio quadro geral de referências dentro do qual se realiza a sua investigação ou a sua análise. No campo das ciências exatas, por exemplo, o grande efeito da "revolução" einsteiniana não parece ter sido, apenas, a superação do sistema cosmológico de NEWTON, mas a revelação da necessidade científica de uma contínua crítica dos pressupostos da investigação física. Já no terreno da vida social, constitui uma banalidade reconhecer que o aperfeiçoamento do sistema de comunicações de massa conduz a uma tal acumulação de informações, que a necessidade de uma ordenação preliminar do pensamento surge como princípio de sobrevivência da razão. Especificamente, em matéria de ensino, essa transformação radical do sistema de comunicações pôs fim, obviamente, ao antigo monopólio institucional atribuído à família ou à escola. O educando, agora, é continuadamente "bombardeado" com informações de todos os níveis e provenientes de todos os azimutes sociais, sentindo, mais do que nunca, a indispensabilidade de um método de pensamento que o habilite a criticar e classificar essas informações, segundo um plano racional.

\section{O Direito e as Finalidades Sociais do seu Ensino.}

Se o método consiste, portanto, na direção correta para se chegar a um resultado, em se tratando do método do ensino jurídico é preciso, antes de mais nada, saber qual o resultado que se quer atingir, ou seja, quais as finalidades sociais do ensino do Direito e, também, obviamente, em que sentido se fala em Direito.

No que se refere à estrutura do fenômeno jurídico, não parece exagerado reconhecer que, hoje, vai se estabelecendo um largo acordo a respeito do seu caráter tridimensional. Pode-se divergir auanto à importância de cada uma dessas dimensões - normativa, sociológica ou valorativa - na composição do tod.o; mas a supressão de qualquer delas é ressentida, geralmente, como uma mutilação.

Sob o aspecto funcional, há também um razoável consenso no sentido de que o Direito visa à convivência harmônica dos homens, seja pela composição de conflitos de interesse já manifestados, seja pela previsão de conflitos futuros. No primeiro caso, os modelos de harmonização social apresentam um caráter "processual" e conservador; no segundo, um caráter "político" e criador. 
Advirta-se, desde logo, que esses gêneros de modelos jurídicos não correspondem, de forma alguma, à tradicional dicotomia direito público e direito privado. Os modelos "políticos" não são privativos do primeiro, da mesma forma que os modelos "processuais" não são exclusivos do segundo. Assim, para ficarmos no exemplo histórico a que sempre se recorre, a evolução do direito romano, até a época republicana, acusava no direito privado um caráter "processual" e conservador, enquanto o direito público aparecia como predominantemente inventivo e transformador. No período pós-clássico, com o reforço do poder político central, os papéis se invertem, observando-se maior rigidez nos esquemas de realização do direito público (com a conseqüente multiplicação de crises) e maior flexibilidade e intervencionismo em matéria de direito privado, com a proliferação de rescritos imperiais e o estabelecimento de uma cognitio extra ordinem no processo.

Em qualquer dessas funções, porém, resulta claro que o Direito só pode ser pensado in concreto, dentro de um sistema de possibilidades reais. A evolução histórica tem demonstrado que a harmonia social não é um dado pré-fabricado, uma espécie de direito natural de forma abstrata e conteúdo variável, mas a conciliação delicada e sempre precária de interesses múltiplos e complexos, num contexto histórico determinado. Como reflexo da vida humana, a ordem jurídica não pode ser experimentada in vitro.

Quanto às finalidades do ensino jurídico, observa-se um aparente antagonismo entre a formação generalizadora e desvinculada de compromissos profissionais, de um lado, e o ensino profissionalizante de outro. $\mathrm{O}$ primeiro tipo de formação, diz-se, pertenceu ao passado, era próprio de uma sociedade pré-industrial e elitista. Estava na origem do bacharelismo. $O$ ensino profissionalizante, ao contrário, seria o único adaptado às necessidades de um país que deseja desenvolver-se, tanto econômica quanto social e politicamente, no sentido de uma maior igualdade de oportunidades.

Pessoalmente, não vejo antagonismo entre essas concepções, que apresentam, cada qual, virtudes e defeitos. Penso que o ensino jurídico não pode buscar, exclusivamente, uma ou outra dessas finalidades, mas, ao contrário, procurar, em ambas, desenvolver as suas virtudes e reduzir os efeitos sociais de suas carências. Parece óbvio que, sendo o diploma de bacharel em Direito um requisito legal para o exercício de várias atividades, ofícios ou profissões, as Faculdades de Direito não podem se dar ao luxo de organizar o seu ensino, unicamente, no sentido 
da formação de "especialistas em generalidades". A arte profissional deve estar, constantemente, na mira de professores de Direito, como uma das metas da organização do ensino. Mas, também, por outro lado, como a melhor tradição humanística nos ensina, o estudo do Direito é um dos componentes indispensáveis da formação cívica, dessa educação para a polis, cuja ausência é tão cruelmente sentida numa civilização tecnológica de massas. De resto, por uma aparente contradição, tão própria de esquemas mentais mal elaborados, os propugnadores de um ensino profissionalizante são os mais severos críticos do "produtivismo capitalista" em matéria educacional; e os adeptos do "ensino humanístico" não deixam de censurar o aspecto elitista das nossas Universidades.

Já é tempo de conjugar ambas essas finalidades em um quadro educacional suficientemente compreensivo e aberto, para abrigar as mais diferentes vocaçōes.

\section{Carências da Atual Metodologia.}

Se essa visão do fenômeno jurídico não se afasta muito da realidade, parece irrecusável que a metodologia do ensino do Direito, entre nós, tem sido largamente inadequada. De modo geral, prevalece o método da explicação de normas legais em sua estrutura abstrata, sem referência quase nenhuma à sua função no contexto social. A concretização da norma, quando se verifica, é no esquema de conflitos de interesse já instalados e julgados. Nesse esquema abstrato e "processual", o discente, na grande maioria dos casos, é instado a receber as soluções do chamado direito positivo, sem nenhuma contribuição crítica ou criadora. Na melhor das hipóteses, é levado a "redescobrir" a resposta já existente e completa na ordenação jurídica, sob a enganosa aparência de "julgamento"; quando já se sabe, hoje, que a função jurisdicional não é simples revelação de soluções já prontas, mas construção de justiça para o caso concreto.

Assim, de um lado, no esquema "processual" falta o treino da verdadeira concretização do juízo jurídico, na consideração das complexas circunstâncias de cada caso, como se o Direito se reduzisse a uma lista de receitas. De outro, raríssimas vezes se tenta uma metodologia da criação jurídica, essa ars combinatoria que faz apelo à imaginação e ao espírito inventivo. Ora, em certos ramos da advocacia, como a empresarial por exemplo, a construção de soluções jurídicas novas se impõe a cada dia. 0 que se pede ao advogado, aí, não é apenas a indicação do lícito e do ilícito, a informação sobre o estado da jurisprudência, 
mas a criação de esquemas harmônicos e sob medida para o caso concreto, esquemas que a doutrina ainda não imaginou nem os tribunais julgaram.

Por outro lado, no tocante à finalidade de formação cívica, o ensino do Direito - tanto aqui como alhures, aliás - carece de uma adequada visão sociológica dos institutos jurídicos e de sua crítica axiológica, em função das necessidades e aspirações próprias, de cada povo e cada época histórica, em pról de maior justiça. É significativo observar, assim, como os estilos dogmáticos revelam, em sua petrificação histórica, os esquemas mentais que os originaram. Na tradição do ensino jurídico francês, por exemplo, o estilo doutrinário é francamente dissertativo. A tese de doutoramento - pièce de résistance de todo candidato ao magistério - é, classicamente, dividida em duas partes que não se opõem, nem mesmo artificialmente, para dar lugar a uma "superação" final, nos moldes da tradição sorbonneana, mas se completam. 0 estilo é, naturalmente, expositivo e nãocrítico; menos ainda inventivo. Na Itália, predomina o abstracionismo conceitual. No Brasil, o gênero doutrinário mais prezado pela prática profissional consiste nos comentários a textos de lei. Mas em nossos meios acadêmicos persiste, curiosamente, a tradição "científica" inaugurada pelos pandectistas, na segunda metade do século XIX, como reação à escola da exegese, desenvolvida em função do movimento de codificação napoleônica. 0 abstracionismo sistemático e conceitual é sempre apresentado, orgulhosamente, como produto da "ciência" e oposto ao pobre casuísmo da praxe forense.

Em todos esses estilos, afinal, transparece com nitidez o desprezo pelas dimensões sociológica e valorativa do Direito. Com isto, a "ciência" jurídica reduzir-se-ia a mero exercício de lógica formal e organização sistemática de conceitos (quando realmente se atinge esse resultado, o que nem sempre acontece...). Parece indispensável que os Professores de Direito tenham uma consciência clara dessa diferença e dos verdadeiros títulos racionais do conhecimento jurídico, a fim de evitar não só essa ridícula pretensão "científica", como o ceticismo antiracional de muitos profissionais bem sucedidos.

A aplicação do método próprio das ciências da natureza ao conhecimento do homem e das realidades humanas constitui, ainda hoje, um erro tanto mais funesto quanto menos aparente. Ele surge agora, com redobrado vigor, na corrente anti-historicista liderada por KARL POPPER. Se a tentação da reductio ad unum tem sido permanente na história do pensamento, o seu perigo torna-se manifesto nos dias que correm, em razão do 
formidável prestígio da tecnologia triunfante. $O$ que não é redutível aos esquemas das ciências exatas não é racional. Parafraseando HEGEL, poder-se-ia dizer que, para o homem moderno, todo natural é racional e todo racional é natural. Com isto, ou se dilui o fenômeno humano na natureza ou se evacua o homem do universo racional.

\section{Os Precursores do Novo Método.}

É interessante observar, no entanto, como nos primórdios do grande movimento científico, duas inteligências de primeira grandeza - PASCAL e VIC0 - procuraram dar ao conhecimento das coisas humanas foros racionais de autonomia, em relação à simples lógica ou às ciências da natureza. Não parece demasiado relembrar, aqui, o seu pensamento, pelo menos como a demonstração de que os novos métodos do ensino do Direito não são uma ousadia do nosso tempo.

$\mathrm{Na}$ distinção pascalina entre esprit de géométrie e esprit de finesse já se apontam todos os elementos da antinomia metodológica, explicitados nos séculos seguintes: pensamento abstrato e julgamento concreto, unidade e pluralidade de princípios, razão lógica e razão axiológica. No esprit de géométrie, os poucos princípios são palpáveis, mas afastados do uso comum. No campo do esprit de finesse, ao revés, os princípios são tão sutis e em tão grande número, que é quase impossível vê-los todos, mesmo para quem é dotado de boa visão. Na verdade, esses princípios, aí, são antes sentidos do que vistos. É preciso possuí-los de uma só vez e não progressivamente, por via de raciocínios. Eis por que é raro que o geômetras sejam espíritos finos e os espíritos finos sejam geômetras. Estes últimos, querendo tratar geometricamente as coisas finas, se tornam ridículos, pois o conhecimento dessas coisas não se adquire por definições e raciocínios. PASCAL sentia, pois, a especificidade dos valores e a necessidade da intuição como forma de conhecimento. À lógica da conseqüência, desenvolvida por meio de proposições, antevia a lógica do preferível, que implica sempre um julgamento, isto é, uma escolha entre possibilidades.

Por esse caminho entreaberto enveredou GiambatTista VICo meio século após, fazendo da instituição das ciências do homem a querela de toda a sua vida. Precisamente, na lição inaugural da Universidade do Reino de Nápoles, em 18 de outubro de 1708, desenvolveu as bases da nova metodologia. Retomando, como tema retórico, a clássica disputa entre antigos e modernos, que ocupara boa parte da atividade intelectual do 
século XVIr, propôs-se, aparentemente, a demonstrar a excelência do método antigo. Na verdade, sob a aparência de uma defesa e ilustração do pensamento clássico, lançou os fundamentos dessa "ciência nova", adaptada ao conhecimento da realidade humana.

VICo principia por assinar um campo preciso e limitado à "nova crítica" (o método cartesiano), que passara a empolgar os espíritos. Observou que ela servia tão-só para aprender as coisas certas, o mundo físico, sendo propriamente imprestável para captar a realidade humana, que é o mundo do verossímil. A este último, só se pode aceder por meio da prudência, cuja extrema dificuldade e delicadeza não escapara aos antigos. A geometria, para estes, não passava de uma espécie de "lógica infantil", enquanto a prudência exigia redobrado esforço, pois implicava, de certa forma, que se "forçasse" a natureza pela imaginação e não apenas se a descobrisse pela análise.

Ora, o método próprio da prudência é a tópica (retórica ou arte da argumentação), que procede por totalidades e acumulação de razões, e não por meio de análises em busca de uma razão última. Pois, se a finalidade do método cartesiano é a verdade e a certeza, a finalidade da retórica é a persuasão. A verdade, com efeito, é uma só, ao passo que as verossimilhanças são muitas e os erros infinitos.

Não se trata, por conseguinte, de substituir um método ao outro, mas de saber manejar habilmente um e outro, conforme o objeto de conhecimento. VIco percebe com clareza as limitações de ambos e as suas más inclinações, por assim dizer. É um fato que a antiga tópica acabava aceitando, facilmente, o erro, enquanto a nova crítica repele o mundo das verossimilhanças. Daí preconizar a utilização de um método mais completo, o qual, enriquecido com os argumentos da tópica, soubesse, ao mesmo tempo, "cultivar o bom senso e conduzir à prudência civil e à eloqüência; além de desenvolver a fantasia e a memória, encorajando, com isso, as artes que subsistem mediante essas faculdades da mente; e, somente por último, cultivar a crítica (cartesiana)"

Enfileirando-se entre os defensores do humanismo clássico, sustenta que o mais grave inconveniente dos estudos da época era a preocupação com as ciências naturais, deixando-se as ciências humanas (morais) relegadas a plano secundário, sobretudo aquela parte das ciências morais que trata da índole da alma humana e também a ciência do Estado. "Hoje", proclamava, "o único fim dos estudos é a verdade; o que nos leva a investigar a natureza que nos circunda, porque parece certa, e 
não a nossa natureza humana, que pelo livre arbitrio faz-se incertíssima. Com isto, esse método de estudos engendra, entre os jovens, o grave inconveniente de não fazê-los agir com suficiente prudência na vida cívica (...)".

E a prudência a virtude magna da vida social, pois "as coisas humanas são dominadas pela ocasião e pela escolha, uma e outra incertíssimas". Na ciência, distinguem-se os que buscam uma causa única, à qual possam reduzir todos os fenômenos naturais; enquanto na "prudência civil" ilustram-se os que, diante de um fato, investigam o maior número possível de causas, para discernir, dentre elas, qual a decisiva, conforme as circunstâncias do caso concreto. Nas coisas humanas, há pois duas atitudes a evitar: a "racionalidade retilínea" das ciências exatas e a submissão ao capricho e ao acaso, tão freqüente no homem comum. A verdade das coisas humanas não é apenas o domínio do ser, mas também o do aparecer: é manifestação do ser enquanto aceito como tal pelo consenso dos homens, segundo o critério supremo do convívio ou socialidade. Por isso, certissimamente, os romanos se manifestavam, nessas matérias de prudência, seja como jurisconsultos, seja como senadores, por meio de pareceres (videri ut...).

Quanto ao método próprio da jurisprudência, Vrco lembra que ela era, na Grécia, tripartida em filosofia, praxe e retórica, enquanto em Roma a sabedoria dos jurisconsultos distinguia-se, cuidadosamente, da arte dos advogados. A época moderna, porém, unificou a jurisprudência, produzindo um resultado ambígüo. De um lado, o advogado tende a conhecer melhor o Direito, o que é uma vantagem. De outro lado, porém, a jurisprudência torna-se "esquelética", pela falta de eloqüência, e se enfraquece com a ausência de uma segura orientação filosófica.

\section{A Lógica Própria do Saber Jurídico.}

Precisemos, agora, mais exatamente, o tema destas reflexões. O método do ensino jurídico será uno ou múltiplo? A pluralidade de métodos válidos, no mesmo tempo histórico, só existirá na medida em que houver mais de um objeto dentro no qual aplicar essa direção correta ou caminho apropriado. E, efetivamente, o Direito, em sua realidade tridimensional, tanto pode ser objeto de ciência (conhecimento racional), como de arte. Embora ambas existam como momentos de implicação recíproca, tendo por objeto, largamente, idêntico fenômeno social, distinguem-se quanto à função que cada qual exerce. Nesse sentido, o método jurídico não é, apenas, uma via ratio- 
nalis inquirendi, mas também uma via rationalis operandi. E o método de ensino do Direito não pode deixar de se fundar tanto na lógica própria dessa ciência ou sabedoria, quanto na técnica adequada dessa arte.

Os desenvolvimentos doutrinários mais recentes têm revelado que a lógica própria do Direito, enquanto processo ordenado de conhecimento, distingue-se, nitidamente, do procedimento silogístico ou raciocínio por conseqüência. Neste, a conclusão é uma só, ainda que as premissas não sejam verdadeiras. Uma vez postas estas, portanto, a conclusão decorre necessariamente (salvo erro grosseiro de raciocínio), como conseqüência implícita, sem qualquer acréscimo ou invenção. A lógica jurídica, diferentemente, é a da decisão e da escolha entre várias possibilidades; a lógica da preferência e não da conseqüência, revelando, pois, a sua índole voluntarista e axiológica (o que não significa, de modo algum, irracional). A norma geral, assim como a decisão particular, não é objeto de demonstração, mas de justificação. No procedimento desta, o sujeito que comanda, interpreta ou decide contribui, necessariamente, para a solução dada, com a sua vontade e as preferências axiológicas, próprias ou da sociedade em que vive.

A razão fundamental dessa diferença parece residir no fato de que as ciências da natureza constituem o domínio da objetividade (ou, se quiser, da unisubjetividade, para se não olvidar a necessária implicação sujeito-objeto em todo processo de conhecimento) ; enquanto o Direito, tal como a política, supõe a intersubjetividade, isto é, a interferência vital de mais de um sujeito. A demonstração científica deve ser apodítica; à justificação jurídica, porém, basta ser convincente, pois aquela busca a verdade, enquanto esta se contenta com verossimilhanças.

A discutibilidade de normas ou decisões jurídicas não pode ser totalmente eliminada, a não ser mediante um acordo de vontades, pois não há critério físico ou "natural" que elimine as preferências subjetivas.

0 valor educacional dessas asserções me parece evidente. Com efeito, a pretensão de descobrir a verdade, no campo da moral social e do Direito, apresentando-a sob a forma de evidência unicamente recusável por espíritos desonestos ou viciados, constitui a matriz de todos os totalitarismos. Em direção oposta, a prática do método dialético e da técnica argumentativa, para se chegar a um acordo entre partes com interesses distintos, representa a grande escola de convivência social, D primeiro e fundamental aprendizado da democracia pluralista. 
A justificação do decisório na sentença, sob pena de nulidade (Código de Processo Civil, art. 458 II), e o dever imposto ao magistrado, ao aplicar a norma, de atentar para os fins sociais a que ela se destina e as exigências do bem comum (Lei de Introdução ao Código Civil, art. $5^{\circ}$ ) inserem-se nessa lógica própria do juízo jurídico, feita de razão voluntarista e axiológica. PASCAL, aliás, já assinalara, em matéria de fé (ou seja, de confiança, tão importante na vida do Direito), essa interferência da vontade, sem importar em irracionalismo. $L a$ volonté, observou, est un des principaux organes de la créance (leia-se croyance); non qu'elle forme la créance, mais parce que les choses sont vraies ou fausses, selon la face par où on les regarde. La volonté qui se plaît à l'une plus qu'à l'autre, détourne l'esprit de considérer les qualités de celles qu'elle n'aime pas à voir; et ainsi l'esprit, marchant d'une pièce avec la volonté, s'arrête à regarder la face qu'elle aime; et ainsi il en juge par ce qu'il voit (Pensées, ed. Brunschvicg, n.0 99).

No campo jurídico, o arbítrio da vontade na decisão individual é limitado pelo quadro legal, assim como o arbítrio do legislador é circunscrito pelo quadro constitucional. Mas dentro desses limites, a vontade não só pode como deve se manifestar na criação e na aplicação da norma, pela eleição de uma dentre várias possibilidades.

Daí por que o ensino jurídico não deve se mover, unicamente, na área das certezas, mas também suscitar a dúvida, como método de pensamento. Já se assinalou que a dúvida difere, radicalmente, da ignorância, que é um estado não apenas negativo mas, sobretudo, passivo. É a quietação no não-saber, máxime quando o ignorante não sabe que ignora. Quem duvida, ao revés, já principia por perceber que não sabe e não se conforma com esse estado negativo. Procura uma via ou direção para chegar ao saber. Toda dúvida, pois, se resolve num método, da mesma forma que todo método supõe a dúvida, como disposição de procura. A contribuição genial de DESCARTES, na história do pensamento, consistiu, justamente, em apontar esse caminho simples e direto para resolver as inquietações do "outono da Idade Média". É a dúvida metódica.

Nesse ponto, frise-se que um dos grandes vícios do estilo tradicional de ensino do Direito é o de evitar, sistematicamente, a dúvida. A esse desempenho de pobre auto-suficiência se chega por dois caminhos diversos. 0 primeiro consiste em supor, escolasticamente, que assim como todas as hipóteses de fato estão previstas no sistema de direito positivo - o postulado clássico da inexistência material de lacunas - assim também toda inda- 
gação especulativa encontra resposta na ciência jurídica, e uma só resposta. A outra maneira de se evitar a dúvida fecunda consiste em apresentar, ceticamente, a multiplicidade infindável de soluções - legais, jurisprudenciais ou doutrinárias - para justificar a escolha individual e "livre" de qualquer decisão. Uma espécie de adaptação, ao mundo jurídico, do lugar-comum de gustibus non disputandum. De ambos os modos, desencoraja-se, no educando, o hábito de pensamento criador e a confiança na razão jurídica; pois toda criação, nesse campo, só pode ser racional, isto é, justificável segundo critérios aceitáveis pelas demais inteligências.

$O$ verdadeiro método de pensamento jurídico parte da inquietação, requer a dúvida como ponto de partida, mas se resolve sempre na escolha mais justa, isto é, socialmente mais apta a pacificar os espíritos. Isto supõe, necessariamente, um quadro objetivo de referências a ser respeitado, anterior e superior à vontade das partes, como elemento garantidor da certeza e da segurança, indispensáveis ao convívio humano.

Foi exatamente nessa linha de pensamento que se situou HANS KELSEN em suas considerações finais a respeito da interpretação jurídica, na Teoria Pura do Direito. A interpretação da norma consiste no delineamento da moldura, dentro da qual cabem as diferentes possibilidades. E a aplicação da norma é uma escolha, um ato de vontade, elegendo a interpretação preferível no caso concreto, mas sempre dentro da moldura legal. Ele critica, com razão, a opinião largamente aceita, de que uma norma comporta sempre e necessariamente uma única interpretação: a interpretação "correta". É por força dessa ficção ideológica que a história das doutrinas jurídicas e a evolução das correntes jurisprudenciais aparecem geralmente, aos olhos dos estudantes, como autêntica "comédia de erros", como disse ASCARELLI.

Mas embora se rejeite a lógica do dualismo "verdade erro" na interpretação das normas jurídicas, admitindo-se a sua plurissignificação e, portanto, a possibilidade jurídica de várias leituras, é bem de ver que, mesmo in abstracto e em termos gerais, há sempre uma interpretação melhor, isto é, preferível às demais. $\mathrm{E}$ essa preferência funda-se numa justificação de ordem valorativa, nem sempre consciente ao próprio intérprete.

justamente por se fundar nessa lógica voluntarista e axiológica que o Direito parte de um acordo de vontades e visa sempre a um acordo de vontades. Mesmo quando a solução do conflito de interesses se revele impossível sem o concurso de 
uma vontade externa e superior à das partes, deve-se sempre, como condição legitimadora da ordem social, pressupor a existência de um acordo fundamental quanto à solução de litígios particulares por uma autoridade soberana. Nesse particular, como salientou LÉVI-STRAUSS, a antropologia e a sociologia contemporâneas trazem um apoio considerável à intuição fundamental do "Contrato Social", apresentada por Rousseau.

Mas se essa lógica da preferência difere, sensivelmente, da lógica da conseqüência, é preciso evitar qualquer adesão ao irracionalismo e supor que, no campo do Direito, não há lugar para os procedimentos tradicionais da análise conceitual, das classificações sistemáticas e do encadeamento rigoroso de proposições. Seria isso desconhecer as próprias matrizes intelectuais da jurisprudentia, como saber autônomo, em Roma, sob o influxo da filosofia grega. Todo o impressionante trabalho de construção doutrinária do Direito Romano - que ainda hoje admiramos como um dos grandes monumentos culturais da humanidade - fundou-se no mecanismo, afinal bem simples, de differentiae, distinctiones ou divisiones, de um lado, e de regulae e definitiones, de outro.

O saber jurídico não repudia, pois, a lógica formal ; simplesmente, não lhe atribui uma função exclusiva no raciocínio. Mas sem o respeito à lógica formal não há saber algum nem tampouco possibilidade, ainda que remota, de transmissão do saber, ou seja, de cultura. A linguagem da comunicação racional é, estruturalmente, moldada pelos princípios lógico-formais. Seria um funesto desvio abandonar essas exigências elementares de racionalidade, para aderir a um modismo intelectual qualquer.

Por outro lad.o, não se pode deixar de assinalar que a tentativa de aplicação em Direito da tradicional antinomia entre o método dedutivo e o indutivo perde sentido quando se admite a estrutura tridimensional do fenômeno jurídico. A simples dedução de uma conclusão, pela análise da norma geral e a qualificação do caso concreto, é tão insuficiente para a justa composição dos conflitos de interesse, quanto a expressão de uma solução normativa a partir do levantamento estatístico dos fatos ocorridos. E mister habituar o aluno a harmonizar a análise do texto normativo, não só com a consideração das peculiaridades do caso concreto, mas também com as exigências ético-sociais do momento histórico. 0 que exige, obviamente, muito maior esforço didático e preparação cultural do professor. 


\section{o Método do Ensino da Arte Jurídica}

Saldemos agora, antes de prosseguir, o balancete das reflexões até aqui expostas. Vimos que a lógica própria do saber jurídico - e que deve, portanto, ser ensinada em suas bases racionais e aplicada sistematicamente, em nossas Faculdades de Direito - é a da preferência, cuja meta não consiste na demonstração de uma verdade "objetiva", mas na justificação de uma escolha. Vimos, igualmente, que essa justificação axiológica só tem sentido no contexto de um acordo de vontades, o qual não se obtém, perfeitamente, senão por via de convencimento.

Resulta de tudo isso a importância considerável da técnica da argumentação, como instrumento da arte jurídica. A sua ausência nos programas e métodos de ensino do Direito, nos últimos tempos, constitui uma das mais sérias razões do despreparo de nossos bacharéis para o exercício de uma profissão jurídica.

A teoria da argumentação representa o que a tradição aristotélica denominou "retórica". O retórico, na definição clássica, é o vir bonus dicendi peritus. Dois elementos devem ser ressaltados nessa definição: a boa formação da personalidade humana (vir bonus) e a habilidade ou proficiência na arte da expressão verbal (peritus dicendi).

A destreza retórica supõe, em primeiro lugar, a boa formação da mentalidade jurídica, em função dos grandes valores que devem enformar toda a ordem social: a justiça, a ordem, a segurança, a liberdade. É aí que faz sentido, justamente, pensar no ensino do Direito como destinado, também, à preparação para a vida cívica e política, como salientei acima. E é aí, igualmente, que se verifica o grave erro pedagógico de relegar às trevas exteriores nas Faculdades de Direito, com a invocação do lugar comum de que aos estudantes cabe estudar e não "fazer política", todos os debates em torno da legitimidade de nossa ordenação jurídica. Que "formação moral e cívica" é esta, capaz de impedir as novas gerações de exercitar o seu livre julgamento moral e a sua escolha cívica? A institucionalização desse debate tem que ser feita nas Faculdades de Direito, educando-se os alunos à pluralidade de preferências e ao recurso às análises críticas, que não são meras "paixões do cérebro", mas sim o "cérebro das paixões", como escreveu o jovem MARX na Crítica à Filosofia do Direito de Hegel.

A habilidade ou proficiência na arte da expressão verbal significa, antes de mais nada, como é óbvio, o domínio grama- 
tical e estilístico da língua. Nesse sentido, a antiga formação literária do curso secundário, abandonada em proveito de pseudo-exigências tecnológicas e de um desastroso "objetivismo" do exame vestibular, representava uma preparação muito mais inteligente aos cursos jurídicos do que o atual empilhamento caótico de noções mal digeridas, realizando em sua plenitude o ceticismo do poeta: "estudar é uma coisa em que está indistinta a distinção entre nada e coisa nenhuma."

Tradicionalmente, a realização do discurso retórico se decompõe em cinco elementos: inventio, dispositio, elocutio, memoria e pronunciatio. Para os efeitos da argumentação jurídica, os três primeiros são os mais importantes.

A inventio é a elaboração das idéias, dos argumentos. É a parte do raciocínio jurídico, propriamente dito, consistente nas razões justificadoras da solução escolhida.

A dispositio consiste na organização dessas idéias ou argumentos pela forma mais adequada, tendo em vista o destinatário da argumentação (juiz togado, júri popular, empresário, sindicato operário, administração pública, etc.). A força de convicção de cada argumento varia, com efeito, segundo a mentalidade da pessoa a convencer e o seu meio social. É preciso, pois, descobrir a ordem mais adequada de apresentação, que pode consistir na acumulação do maior número possível de razões ou, ao contrário, na insistência inicial em um ou dois argumentos, apenas, guardando-se os demais para um momento ulterior; na ordenação dos argumentos segundo um critério de importância crescente ou decrescente.

A elocutio é a busca da melhor forma expressional, do estilo mais adaptado ao assunto, ao objetivo e ao destinatário. É nesse ponto que a carência de formação literária e artística de nossos bacharéis se faz, cruelmente, sentir. 0 estilo de "boca de forum" - amálgama de fórmulas praxísticas, expressões latinas e frases feitas - é o único praticado pela grande maioria dos advogados, qualquer que seja o auditório ou a circunstância.

Urge, pois, voltar o quanto antes ao estudo da retórica original, que é tão distante da retórica decadente da idade barroca, quanto a lógica grega o é da escolástica de fins da Idade Média.

Mas a arte jurídica não supõe, apenas, a mestria da técnica argumentativa. Ela exige, também, o correto emprego de uma faculdade humana até há pouco totalmente desconsiderada no campo científico, pelo pensamento positivista: a imaginação. 
É curioso assinalar que, no mesmo ano de 1950, a humanidade chegou ao supra-sumo da objetivação do raciocínio lógico e matemático, meramente reprodutivo, com o lançamento do primeiro computador UNIVAC I; ao mesmo tempo em que se reconhecia, pela primeira vez, a importância decisiva da imaginação para o progresso da ciência, com o resultado das pesquisas de J. P. GUILFORD e seus colaboradores, nos Estados Unidos (The Relation of Intellectual Factors to Creative Thinking). Desde então, a preocupação com a "criatividade", como componente da personalidade psicológica, tem sido constante.

Ora, a capacidade imaginativa sempre foi elemento indispensável no processo de criação jurídica, seja no campo legislativo, seja no terreno da prática administrativa e contratual, seja na própria atividade judicante. Nesse trabalho de "engenharia social", para usar da expressão de ASCARELLI, não se cuida de descobrir o dado jurídico, mas de inventar soluções ainda não compreendidas no estado atual da evolução do Direito. A fecundidade dos juristas, advogados e magistrados brasileiros, quanto a isso, está longe de ser desprezível. A posse de direitos pessoais, para suprir a inexistência de remédios jurídicos adequados; a ampliação do "habeas-corpus" à proteção de liberdades outras que não a de simples ir e vir; a elaboração do mandado de segurança; a concessão de medida liminar no habeas-corpus, pelo Regimento Interno do Supremo Tribunal Federal, analogamento ao procedimento do mandado de segurança; a correção monetária de dívidas de valor face ao surto inflacionário posterior a 1945; a legítima defesa putativa na vigência da Consolidação das Leis Penais de VICENTE PIRAGIBE, que a desconhecia; a transformação das gratificações natalinas em décimo-terceiro salário, pelo mecanismo da habitualidade; o reconhecimento do instituto da sociedade de fato para evitar injustiças na partilha patrimonial, por ocasião da cessação do estado de concubinato, num país que desconhecia o divórcio, tendo recebido apreciável contigente de imigrantes e sofrido grandes correntes migratórias internas - tudo isso e tantas outras criações da prática atestam a incontestável vitalidade de nossa imaginação jurídica.

Pois essa disposição mental criadora - a disciplina da fantasia para transformá-la, pelo acréscimo da previsão controlada, em autêntica imaginação - também se ensina. A finalidade das Faculdades de Direito não pode, por conseguinte, cingir-se a transmitir conhecimentos, mas deve também propiciar aos educandos a aquisição de adequadas atitudes mentais. 


\section{Sugestões}

Com fundamento nas observações feitas, é possível, à guisa de conclusão, apontar algumas sugestões para o aperfeiçoamento dos atuais métodos do ensino jurídico. Parece ocioso, no entanto, assinalar que não se trata, absolutamente, de soluções de resultado automático ou de receitas de efeito mecânico. A nenhum professor escaparão, por certo, os graves acentos de verdade contidos na reflexão que EMILE FAGUET: Au fond de l'education, comme au fond de toutes choses humaines peut-être, il y a une contradiction essentielle (...). Nous enseignons à écrire, et tout style qui n'est pas original n'est pas un style; nous enseignons à penser, et toute pensée que nous tenons d'un autre n'est pas une pensée, c'est une formule; et toute méthode pour penser que nous tenons d'un autre n'est pas une méthode, c'est un mécanisme. Nous enseignons à sentir, et tout sentiment d'emprunt est une affectation, une hypocrisie, une déclamation. Não nos devemos predispor, obviamente, a um ceticismo desabusado, recusando fé nas virtudes da educação. Mas também não podemos dar guarida, no melhor estilo do tecnicismo contemporâneo, ao otimismo ingênuo e superficial dos que cuidam que lidar com a nobre matéria humana é algo de semelhante à manipulação de insumos industriais. $O$ objetivo de toda verdadeira educação não é o mimetismo do adestramento, mas a plena criatividade da pessoa humana, no desenvolvimento harmônico de suas faculdades.

As recomendações que se seguem procuram atender, mais especificamente, à situação própria da Faculdade de Direito da Universidade de São Paulo. Fica subentendido, no entanto, que grande parte do êxito na reformulação da metodologia didática depende de uma revalorização do ensino primário e secundário, abandonado às trevas exteriores pelos Poderes Públicos, desde há muitos anos. A única influência que as Faculdades de Direito poderiam ter, nesse campo, é indiretamente através dos exames vestibulares. Nesse sentido, a primeira recomendação a ser feita consistiria na revisão das normas e critérios do vestibular, na Universidade de São Paulo, procurando-se adequá-lo às exigências do ensino do Direito.

I - A exposição das diferentes matérias deveria desenvolver, com maior amplitude, os princípios e regras gerais, sem se preocupar com normas regulamentares ou de mera aplicação. A rapidez com que evolui o conteúdo do direito positivo e a enorme mole de textos normativos produzidos pelo Estado intervencionista aconselham o professor a dar 
aos alunos antes seguros elementos de orientação, diante do mare magnum normativo, do que informações completas e minuciosas sobre regras de duração precária e efeitos secundários. Aliás, como a experiência demonstra, sem o domínio adequado dos princípios e das grandes articulações do sistema jurídico, é impossível realizar essa "reciclagem" ou atualização periódica dos profissionais do Direito, por meio dos cursos de pós-graduação ou extensão universitária.

Isto não significa perder-se em algum nefelibatismo doutrinário, ou encorajar o aluno a conhecer antes o manual do professor do que a lei em vigor. Trata-se, sem dúvida, de ensinar o direito positivo, mas na sua racionalidade intrínseca. Não basta, pois, saber, como leguleio, se a norma existe, mas por que existe, para que existe e como atua.

É recomendável, em conseqüência, que na disciplina de Introdução ao Estudo do Direito, como já se tenta fazer hoje, possa ser desenvolvida uma verdadeira Teoria Geral do Direito, superando-se a antiga "iniciação enciclopédica" herdada do positivismo comteano. Para tanto, talvez se haja de acrescentar mais um semestre letivo a essa disciplina.

Por outro lado, não seria absurdo pensar na reformulação de nossos programas, de modo a fazer preceder as diferentes matérias de Direito Público e de Direito Privado de um ensinamento das noções fundamentais desses grandes ramos jurídicos, com maior proveito de sua unidade sistemática. $\mathrm{O}$ que se vê, atualmente, é uma certa repetição concorrencial ou contraditória dessas noções fundamentais, em cada disciplina jurídica, pública ou privada, em detrimento da racionalidade.

II - E imprescindível, pois, que os programas das diferentes disciplinas do curso de graduação sejam compostos mediante um acordo interdepartamental, e não fiquem submetidos, unicamente, à deliberação do conselho do Departamento em que se insere cada disciplina.

III - A análise estrutural dos institutos, feita com o maior rigor lógico, deve ser completada com a sua apreciação funcional, recolocando-se cada instituto no contexto histórico em que foi elaborado, e situando-o no ambiente social, político e econômico do presente, a fim de se verificar se e em que medida ainda preenche os objetivos para os quais foi criado. É lamentável que as nossas Faculdades de Direito sejam incapazes de levar a termo pesquisas de sociologia jurídica, máxime quando da preparação de reformas legislativas, de modo a envolver curricularmente, nessas tarefas, o corpo discente. 
IV - A crítica axiológica do sistema jurídico deve ser estimulada e orientada, de forma a se evitar tanto o pseudo-neutralismo político quanto a algaravia sentimental ou a atuação falsamente universitária de grupos de pressão. 0 professor não pode, portanto, se recusar ao debate sobre a justiça do Direito que existe, sob a pobre escusa de que o ensino jurídico se limita à exposição "pura" do sistema em vigor; mas deve também saber formar os sentimentos dos seus alunos e preparar, com sabedoria, o aperfeiçoamento do Direito vigente em função dos grandes valores da pessoa humana.

V - A fim de evitar a tradicional inclinação do estudante à memorização ininteligente de apostilas e manuais, seria recomendável que os diferentes Departamentos preparassem a composição de antologias de textos fundamentais de cada disciplina, incentivando-se o aluno a colher subsídios nas próprias fontes doutrinárias (devidamente expurgadas de suas excrescências), não se contentando com as compilações de segunda mão que ora inundam o mercado dos livros ditos didáticos.

VI - Recomenda-se que os princípios fundamentais da lógica jurídica sejam ministrados desde o início do curso de graduação. Seria igualmente recomendável que da preparação de futuros docentes, nos cursos de pós-graduação, constasse sempre o ensinamento da lógica jurídica.

VII - A formação do raciocínio e do estilo jurídico deve ser procurada, insistentemente, como uma das metas fundamentais do ensino. A experiência tem mostrado as vantagens do método consistente na proposição de problemas que comportam mais de uma solução, para a discussão, pelos alunos, dos méritos e deméritos de cada solução, tanto sob o aspecto lógico quanto à luz das exigências do bem comum e das finalidades sociais da ordem jurídica. $\mathrm{Na}$ obediência a esse método problemático, é preciso sempre estimular a capacidade inventiva do aluno, habituando-o a "construir" a solução mais adequada ao caso, segundo o seu prudente julgamento, mesmo na ignorância das normas legais vigentes. A correção das "construções" propostas, à luz do direito positivo, virá a posteriori.

Deve-se, igualmente, estimular a composição e apresentação de litígios figurados, ou a reprodução de litígios reais, sempre sobre questões da atualidade, comportando o debate contraditório e o julgamento motivados. 
Maior atenção deve ser dada, nas aulas práticas, ao emprego das técnicas próprias da arte de persuasão, seja oralmente, seja por escrito. É óbvio que isso implica uma adequada preparação dos docentes, encarregados de ministar esse tipo de aulas, não se podendo confiá-las a qualquer voluntário.

VIII - E condenável a multiplicação de docentes na exposição seqüencial da mesma unidade disciplinar, durante o semestre letivo. O corpo discente queixa-se, com razão, da enorme incoerência que resulta desse fracionamento expositivo.

IX - Recomenda-se o estudo de horários de aula mais flexíveis. $\mathrm{Na}$ impossibilidade de se multiplicarem as turmas de alunos, reduzindo o número de seus componentes, torna-se praticamente impossível a realização de seminários com a duração de 45 minutos. Com isto, as chamadas aulas práticas tendem a ser mera repetição expositiva das preleções principais.

$\mathrm{X}$ - Impõe-se, urgentemente, a reformulação das provas de aproveitamento, que devem constituir, também, um meio de ensino.

Escusa dizer que os chamados testes de múltipla escolha, pela sua manifesta impropriedade a formar o raciocínio e o estilo jurídicos, devem ser totalmente banidos.

Os exames podem e devem comportar dissertações, porque grande parte da atividade profissional do bacharel em Direito consiste em dissertar (por exemplo, o arrazoado forense). Mas, apesar de representar uma característica comum a todas as dissertações, consistente em tratar a questão proposta sob todos os ângulos, a dissertação jurídica tem a peculiaridade de procurar convencer alguém sobre determinadas soluções ou escolhas. Por isso, não pode afetar um estilo neutro ou abroquelar-se unicamente no argumento de autoridade, por meio da mania citatória, tão típica do bacharelismo. Deve estruturar-se em torno de argumentos bem apresentados, comportando sempre uma opinião pessoal.

Além das dissertações, os exames deveriam consistir, também, na solução de problemas inteligentemente elaborados, com a possibilidade de consulta a fontes doutrinárias $e$ jurisprudenciais, e não apenas à legislação.

Seria altamente recomendável que os examinadores demonstrassem maior rigor na correção das provas, quanto à apreciação da forma gramatical e estilística. Se o hábil manejo 
da língua é um instrumento imprescindível no exercício da arte jurídica, não se pode relegar a forma literária ao nível de questão de segunda ordem, sob a influência de um certo "cientificismo"

No ciclo básico, parece desejável que a seleção dos examinandos se faça em função de sua cultura geral e não, apenas, do conhecimento de teorias ou sistemas expostos em aula. 